\title{
Determination of the power-duration relationship in upper-limb exercises
}

\section{Determinação da relação potência-duração em exercício com membros}

superiores

Domingos Belasco Junior', Fernando R. Oliveira ${ }^{2}$, José A. N. Serafini ${ }^{3}$, Antonio C. Silva ${ }^{4}$

\begin{abstract}
Objectives: To determine the power-duration relationship in upper limb exercises and to investigate the relationships between parameters derived from this function with physiological indicators of aerobic fitness. Methods: Ten healthy men $(26.2 \pm 2.3$ years, $75.0 \pm 11.8 \mathrm{~kg}$, $178.2 \pm 11.5 \mathrm{~cm}$ and $15.0 \pm 5.7 \%$ body fat) performed a ramped test on an arm cycle ergometer with increments of $20 \mathrm{~W} / \mathrm{min}$. Subsequently, five tests with constant load were performed until exhaustion, with 70, 80, 90, 95 and 100\% difference between VT1 and VO, peak. The critical power (CP) was obtained by means of linearization of the power-duration function. Results: The power-duration relationship was described using an adjusted function $(r=0.98 \pm 0.02)$. The $\mathrm{VO}_{2}$ at $\mathrm{CP}(2.66 \pm 0.62 \mathrm{l} / \mathrm{min})$ was higher than VT1 $(1.62 \pm 0.38 \mathrm{l} / \mathrm{min})$ and VT2 $(2.36 \pm 0.59 \mathrm{l} / \mathrm{min})$, but lower than $\mathrm{VO}_{2}$ peak $(3.06 \pm 0.62 \mathrm{l} / \mathrm{min})$. The CP workload $(103.0 \pm 26 \mathrm{~W})$ was significantly different from VT1 $(69.5 \pm 21 \mathrm{~W})$ and $\mathrm{VO}_{2}$ peak workloads (151.0 \pm 26.3$)$, but was no different of VT2 $(103.5 \pm 30.8 \mathrm{~W})$. The association between critical power and aerobic condition indexes were always significant when expressed as $\mathrm{VO}_{2}(0.73$ to $0.78, \mathrm{p}<0.05)$ and in $\mathrm{W}(0.83$ to $0.91, \mathrm{p}<0.05)$. Determination of $\mathrm{CP}$ in upper-limb dynamic exercises is simple and inexpensive, and can be used by physical therapists for prescribing and evaluating upper-limb training programs. Conclusions: The power-duration relationship in upper-limb exercises can be described by a hyperbolic function and it is associated with physiological indicators of aerobic fitness.
\end{abstract}

Key words: critical power; upper limbs; metabolic thresholds.

\section{Resumo}

Objetivos: Determinar a relação potência-duração em exercícios de membros superiores (MMSS) e verificar a relação dos parâmetros derivados dessa função com indicadores fisiológicos de aptidão aeróbia. Métodos: Dez homens saudáveis (26,2 $\pm 2,3$ anos, 75,0 $\pm 11,8$ kg, $178,2 \pm 11,5 \mathrm{~cm}$ e $15,0 \pm 5,7 \%$ de gordura) realizaram um teste de rampa em cicloergômetro de braço com incrementos de $20 \mathrm{~W} / \mathrm{min}$. Posteriormente, cinco testes de carga constante até a exaustão a 70, 80, 90, 95 e 100\% da diferença entre LV1 e o VO $\mathrm{V}_{2}$ pico foram realizados. A potência crítica (PC) foi obtida por meio da linearização da função potência-duração. Resultados: A relação potênciaduração foi descrita pela função ajustada $(r=0,98 \pm 0,02)$. O VO $\mathrm{VO}_{2}$ na PC $(2,66 \pm 0,62 \mathrm{l} / \mathrm{min})$ foi maior do que no LV1 $(1,62 \pm 0,38 \mathrm{l} / \mathrm{min}) \mathrm{e}$ $\operatorname{LV} 2\left(2,36 \pm 0,59 \mathrm{l} / \mathrm{min}\right.$, respectivamente), mas menor do que o VO${ }_{2}$ pico $(3,06 \pm 0,62 \mathrm{l} / \mathrm{min})$. A carga da PC $(103,0 \pm 26,0 \mathrm{~W})$ foi diferente da encontrada em LV1 (69,5 \pm 21 W) e VO 2 pico (151,0 $\pm 26,3$ W), mas não da em LV2 (103,5 $\pm 30,8$ W). A associação entre a PC e esses indicadores de aptidão aeróbia foram todas significantes quando expressas em $\mathrm{VO}_{2}(0,73$ a 0,$78 ; p<0,05)$ e em $W(0,83$ a 0,$91 ; p<0,05)$. A determinação da PC em exercícios dinâmicos de MMSS é simples e de baixo custo, podendo ser utilizada pelo fisioterapeuta na prescrição e avaliação do treinamento de MMSS. Conclusão: A relação potência-duração em exercícios com os MMSS pode ser descrita por uma função hiperbólica e está associada a indicadores fisiológicos da aptidão aeróbia.

Palavras-chave: potência crítica; membros superiores; limiares metabólicos.

Received: 03/03/2009 - Revised: 14/09/2009 - Accepted: 27/10/2009

${ }^{1}$ Undergraduate Physical Therapy Course, School of Health, Universidade Metodista de São Paulo, São Paulo (SP), Brazil

2 Department of Physical Education, Universidade Federal de Lavras (UFLA), Lavras (MG), Brazil

${ }^{3}$ Department of Medicine, Universidade Federal de São Paulo (UNIFESP), São Paulo (SP), Brazil

${ }^{4}$ Department of Physiology, UNIFESP

Correspondence to: Domingos Belasco Junior, Rua Edson Regis, 426, Jd Guarapiranga, CEP 04770-050, São Paulo (SP), Brazil, e-mail: domingos.junior@metodista.br 


\section{Introduction $: \therefore$.}

When assessing and prescribing exercises for prevention of orthopedic, cardiothoracic or neurological lower-limb (LL) dysfunctions and functional rehabilitation among such individuals, it is necessary for physical therapists to know about the physiological basis that characterizes load threshold determinations between upper-limb (UL) work intensity domains. The most commonly used parameters are the physiological transition threshold (PTT) and the maximum oxygen uptake or peak $\left(\mathrm{VO}_{2} \mathrm{max} / \text { peak }\right)^{1}$.

Another parameter used is the power that in theory could be sustained over the long term without fatigue. This is known as the critical power (CP) or critical velocity (CV). It is determined by analyzing the rectangular hyperbolic relationship between power developed (W) and time elapsed until exhaustion $(t)$ for high-intensity and constant load exercises $^{2-4}$. In other words, it appears that when analyzing the resulting equation, the endurance (capability to perform an exercise for a prolonged period of time) relies directly on the curvature constant and inversely on the power applied above $\mathrm{CP}^{2,3}$. Within this context, $\mathrm{CP}$ is found to be above the ventilatory anaerobic threshold (VT1), in which the load is approximately $60-65 \%$ of the difference between VT1 and $\mathrm{VO}_{2} \max$, at least for LL exercises performed by young individuals ${ }^{4-6}$. Thus, Whipp and Ozyener ${ }^{7}$ proposed that VT1 would mark the transition between moderate and high-intensity exercises, and that the $\mathrm{CP}$ would divide intense and very intense domains close to the respiratory compensation point (VT2) ${ }^{8}$. This would extend to the $\mathrm{VO}_{2} \max$ load.

The W- $t$ relationship has been extensively studied in exercises performed using small or large muscle groups at different levels of physical activity, in response to several interventions, even in patients with ventilatory restriction ${ }^{3,9}$. Moreover, as seen in relation to PTT, it has been demonstrated that CP is sensitive to the effects of training. In this respect, there is little data in the literature regarding whether the response to high intensity UL exercises would be hyperbolic ${ }^{10-14}$. In addition, little is known about the relationship between the parameters describing the W- $t$ relationship for UL and other aerobic fitness indicators ${ }^{10}$.

There are significant differences in maximum and submaximal physiological responses to LL exercises, in comparison with exercises that use a smaller amount of muscle mass (notably UL exercises), have already been described ${ }^{15-18}$. Furthermore, LL ergometers are a useful tool for assessing and training individuals with functional limitation of LL movements, or for lung disease and cardiac patients, thereby assisting in the process of cardiopulmonary rehabilitation ${ }^{19}$. In this light, the objectives of the present study were to analyze the power-duration relationship in constant load exercises performed in UL ergometer and to investigate the relationship between parameters that derive from this function and from physiological indicators of aerobic fitness. In addition, this study investigated whether CP for UL can be used as an assessment tool for the endurance and whether, in this type of activity, $\mathrm{CP}$ is associated with $\mathrm{PTT}$ and $\mathrm{VO}_{2}$ peak.

\section{Methods: :}

The sample consisted of 10 young male adults (22 to 32 years of age) with no orthopedic restrictions on performing UL exercises. They were classified as physically active, with scores ranging from 8 to 12 according to the Baecke, Burema and Frijters ${ }^{20}$ physical activity questionnaire. The study was conducted at the Stress Physiology Study Center (CEFE) after its approval by the Ethics Committee of the Federal University of São Paulo (UNIFESP) (040/00). The subjects were included only after they had signed an informed consent statement. A single physician performed a clinical examination on all subjects, composed of full anamnesis and general physical examination.

Anthropometric data on the subjects were obtained using calibrated scales (Filizola, Brazil), and the body mass index was calculated (Table 1). The subjects were then subjected to an incremental ramped test up to the limit of tolerance. The incremental ramping rate $(20 \mathrm{~W} / \mathrm{min})$ was adjusted between the subjects so that the test duration would be between 4 and 10 minutes.

The metabolic, ventilatory and cardiovascular responses during the UL cycle ergometer test (MET 300, Cybex, Lumex, Ronkonkoma, NY, USA) were obtained via an integrated digital system for cardiopulmonary exercise tests (Vista CX, Vacumed, Hans Rudolph, USA). Metabolic and cardiopulmonary variables were obtained and sampled as arithmetic averages of values determined every 20 seconds. The gas analyzers were calibrated before each test by using a precise mixture of gases $\left(16 \% \mathrm{O}_{2}\right.$ and $\left.4 \% \mathrm{CO}_{2}\right)$. The flow meter was also calibrated before each test using a syringe with a preestablished volume of three liters (Wyandotte model 7200, Hans Rudolph, USA), with different flow settings (slow, moderate and fast). The following variables were determined:

Table 1. Mean and standard deviation (SD) values of age, fitness level according to the Baecke, Burema and Frijters ${ }^{20}$ score and body mass index (BMI).

\begin{tabular}{lccc}
\hline & Age (years) & Baecke score & $\mathrm{BMI}\left(\mathrm{kg} / \mathrm{m}^{2}\right)$ \\
\hline Mean & 26.7 & 9.2 & 22.5 \\
\hline \pm SD & 2.8 & 1.2 & 1.4 \\
\hline
\end{tabular}


$\mathrm{O}_{2}$ uptake $\left(\mathrm{VO}_{2}, 1 / \mathrm{min} \mathrm{STPD}\right)$; carbon dioxide production $\left(\mathrm{VCO}_{2} 1 /\right.$ min STPD); respiratory quotient $(\mathrm{R})$; minute ventilation (VE, 1/min BTPS); respiratory equivalent for $\mathrm{O}_{2}$ and $\mathrm{CO}_{2}\left(\mathrm{VE} / \mathrm{VO}_{2}\right.$ and $\mathrm{VE} / \mathrm{VCO}_{2}$ ); partial pressure of $\mathrm{O}_{2}$ and $\mathrm{CO}_{2}$ $\left(\mathrm{PO}_{2}\right.$ and $\left.\mathrm{PCO}_{2}, \mathrm{mmHg}\right)$ and heart rate $(\mathrm{HR}, \mathrm{bpm})$. The $\mathrm{VO}_{2}$ of the final last 20 seconds of the ramp was considered to be the $\mathrm{VO}_{2}$ peak. The VT1 $\mathrm{VO}_{2}$ was estimated by means of the pulmonary gas exchange method, using readings of the $\mathrm{VCO}_{2}$ inflection point in relation to $\mathrm{VO}_{2}$ (modified V-slope) ${ }^{21}$ and using the ventilator method. In this, both $\mathrm{VE} / \mathrm{VO}_{2}$ and $\mathrm{PO}_{2}$ increased, while VE/ $/ \mathrm{VCO}_{2}$ and $\mathrm{PCO}_{2}$ remained stable. To determine VT1, two regions were excluded from the analysis: the initial two minutes of the protocol, when slower $\mathrm{VCO}_{2}$ kinetics affect the relationships of pulmonary gas exchange, and the points beyond the respiratory compensation point $(\mathrm{RCP})^{22}$. The readings were performed independently by two experienced observers who did not know the identity of the subject under evaluation, or the other results relating to this subject. Taking into account that, for rapid-increment protocols, the load corresponding to the $\mathrm{VO}_{2}$ point values is the one that was developed during the preceding time cons$\tan t^{23}$, the VT1 load was considered to be the one manifested 45 seconds prior to the $\mathrm{VO}_{2}$ that was associated with $\mathrm{VT}^{21}$. VT2 was identified by determining the point at which a progressive increase in the equivalent $\mathrm{VE} / \mathrm{VCO}_{2}$ occurred, with a drop in $\mathrm{PCO}_{2}$ and/or a second abrupt increase in VE after VT1, plotted as a function of $\mathrm{VCO}_{2}$.

Subsequently, each subject underwent a set of five different constant load tests performed up to the limit of tolerance: each test was taken on a different day in a randomized sequence. The protocol was composed of five rectangular loading functions, with a minimum interval of three days between loads. The aim was to provide better graphic distribution and greater validity for the $\mathrm{CP}$ and anaerobic work capacity findings ${ }^{3}$. Loads were selected based on the results from the incremental test and they corresponded to approximately $70,80,90,95$ and $100 \%$ of the difference found between the VT1 load and $\mathrm{VO}_{2}$ peak (VT1 - MAX). Workloads that could induce exhaustion before reaching one minute or after a duration of 20 minutes were deliberately avoided $^{3}$. In addition, all the subjects were also tested with a load equivalent to the intercept of the $\mathrm{W}-1 / \mathrm{t}$ relationship. In this load, $\mathrm{VO}_{2}$ behavior was measured by determining the

Table 2. Mean $( \pm S D)$ values of $V 02$ and power (W) at peak effort, $C P$, V0, peak, VT1 and VT2.

\begin{tabular}{lrccc}
\hline & Peak effort & CP & VT1 & VT2 \\
\hline V02 $(\mathrm{I} / \mathrm{min})$ & $3.06 \pm 0.62$ & $2.66 \pm 0.62$ & $1.62 \pm 0.38$ & $2.36 \pm 0.59$ \\
\hline Power (W) & $151.00 \pm 26.30$ & $103.00 \pm 26.00$ & $69.50 \pm 21.00$ & $103.50 \pm 30.80$ \\
\hline
\end{tabular}

$\mathrm{VO}_{2} \mathrm{CP}$, through identifying the time at which $\mathrm{VO}_{2}$ stabilized. This was found to be between 5 and 10 minutes for all subjects.

Finally, all the subjects underwent an additional test at a load that was $5 \%$ greater than the load equivalent to the intercept of the W-1/t relationship. Neither the subjects nor the investigator were informed of the duration of the test or the power that they should develop. The subjects received encouragement from the investigator, to ensure that they would perform the test to the best of their abilities.

The tests were performed with the subjects maintaining a cycling frequency of $80 \mathrm{rpm}$, in accordance with a preestablished protocol for UL ergometry ${ }^{24,25}$. All the tests were preceded by three minutes under baseline resting conditions and two minutes of load-free exercise, during which the ventilatory and metabolic parameters were verified. The time taken to reach fatigue was determined as the interval between the imposition of the load and the point at which the subject could not maintain the required pace of cycling (drop greater than $10 \%)$.

The W-t relationship was linearized by means of a load (in watts) versus the reciprocal of time ( $1 / t)$, i.e.:

\section{$\mathrm{W}=\mathrm{W}^{\prime} / \mathrm{t}+\mathrm{PC}$}

Therefore, the curvature constant ( $\mathrm{W}^{\prime}$, in kJ) and its asymptote $(\mathrm{PC}$, in $\mathrm{W})$ were determined from the slope and the intercept, respectively, of the line obtained from the difference between least squares ${ }^{26}$.

\section{Statistical analysis}

After verifying that the variables presented normal distribution (Kolmogorov-Smirnov test), the means and the standard deviations were identified. The mean values were compared using one-way ANOVA for paired samples. The levels of association between CP, VT1, VT2 and $\mathrm{VO}_{2}$ peak were determined using the Pearson correlation test. For all tests, significance level of $5 \%(\alpha=0.05)$ was established.

\section{Results $: \because$.}

The relationship between the power applied and its respective time duration (W-t) was described by a rectangular hyperbolic function for all assessed subjects, with the following values: $\mathrm{CP}=103 \pm 26 \mathrm{~W} ; \mathrm{W}^{\prime}=7.08 \pm 2.14 \mathrm{~kJ}$; and $\mathrm{r}=0.98 \pm .02$. Table 2 shows the values found for the study variables from the progressive test and in relation to $\mathrm{CP}$. 
The value of $\mathrm{VO}_{2}$ at $\mathrm{CP}\left(\mathrm{VO}_{2} \mathrm{CP}\right)$ was significantly greater than the values found for VT1 $(\mathrm{P}<0.001)$ and VT2 $(\mathrm{p}<0.05)$ and lower than to $\mathrm{VO}_{2}$ peak $(\mathrm{p}<0.05)$. No significant difference in $\mathrm{W}$ was found between $\mathrm{CP}$ and VT2. There were significant associations between the $\mathrm{VO}_{2}$ and $\mathrm{W}$ values at $\mathrm{CP}$ and between the values of these variables at peak effort, VT1 and VT2 (Table 3).

The volunteers continued to perform the rectangular loading test corresponding to $\mathrm{CP}$ for $42.9 \pm 12.9$ minutes. One subject (10\%) could not complete 30 minutes of exercise at CP, reaching fatigue after 20 minutes of exercise. The other subjects tolerated at least 30 minutes in the rectangular test. However, at the load that was $5 \%$ greater than $\mathrm{CP}$, the subjects reached fatigue after $13.7 \pm 1.4 \mathrm{~min}$ (range: 11.7 to $16.0 \mathrm{~min}$ ).

\section{Discussion $: \therefore$.}

There has been a series of discussions regarding the mathematical model that would best represent the relationship between $\mathrm{W}$ and $t^{26}$, the number of loads that would be ideal for composing the distribution of points on the $\mathrm{W}$ versus $t$ graph $^{3}$ and the amount of time for which a CP load would be bearable. The high $r$ values for all subjects demonstrated that by using the reciprocal of time, the relationship was properly linearized with a hyperbolic function. The findings from the present study emphasize that, similar to LL exercises, the relationship between $\mathrm{W}$ and $t$ for UL exercises is hyperbolic (with $\mathrm{r}$ values ranging from 0.94 to $1.00 ; \mathrm{p}<0.01$ ). This assertion can be seen from the high $r$ values that were found through linearization of the relationship between $\mathrm{W}$ and the inverse of time duration $(1 / t)$, in accordance with previous observations made by other authors in LL-related research ${ }^{2,9}$.

$\mathrm{VO}_{2} \max$ is an aerobic index that, when measured during UL exercises, presents values that are around two thirds of the values obtained during LL exercises among healthy individuals $^{27}$. The smaller muscle mass of the UL can cause localized fatigue and cause exercises to be interrupted before the maximum cardiac output is reached. This is why the parameter is named $\mathrm{VO}_{2}$ peak, regardless of whether a plateau is reached ${ }^{21}$.

Loads that led to $\mathrm{CP}$ were calculated as fractions of the difference between maximum power and VT1. $\mathrm{VO}_{2} \mathrm{PC}$ and $\mathrm{VO}_{2}$ peak were associated $(\mathrm{r}=0.73 ; \mathrm{p}<0.05)$, with significant differences between the parameters, of $2.66 \pm 0.617 \mathrm{l} / \mathrm{min}$ and $3.06 \pm 0.619 \mathrm{l} / \mathrm{min}$, respectively. $\mathrm{VO}_{2} \mathrm{CP}$ was also significantly greater and correlated with $\mathrm{VO}_{2} \mathrm{VT1}(1.621 \pm 0.378 \mathrm{l} / \mathrm{min}$; $\mathrm{r}=0.76)$ and $\mathrm{VO}_{2} \mathrm{VT} 2(2.36 \pm 0.587 \mathrm{l} / \mathrm{min} ; \mathrm{r}=0.78)$. The same trend was observed among the loads of these variables, with greater association values found between them (Table 2). These results suggest that the nature of $\mathrm{CP}$ is predominantly aerobic,
Table 3. Level of correlation between V02 and W corresponding to peak effort, VT1 and VT2 in upper-limb cycle ergometry.

\begin{tabular}{lccc} 
& Peak effort & VT1 & VT2 \\
\hline $\mathrm{VO}_{2} \mathrm{CP}(\mathrm{I} / \mathrm{min})$ & 0.73 & 0.76 & 0.78 \\
\hline $\mathrm{WCP}(\mathrm{W})$ & 0.91 & 0.83 & 0.86 \\
\hline
\end{tabular}

as previously reported ${ }^{28,29}$. Reinforcing this model, $\mathrm{W}^{\prime}$ did not correlate significantly to any of the aerobic parameters used $(\mathrm{r}=0.04-0.25)$. This result suggests that these indexes provide different metabolic representations.

VT2 was calculated from the behavior of ventilatory variables during the ramp protocol. At submaximal intensities, this usually reveals $\mathrm{VO}_{2}$ values that are lower than those obtained in rectangular loading functions of longer duration, i.e. over five minutes, like the $\mathrm{VO}_{2} \mathrm{CP}$ measurement that was used in this study. The phenomenon that explains this discrepancy between protocols is the small component of the $\mathrm{VO}_{2}$ kinetics that occurs above VT1. This makes $\mathrm{VO}_{2}$ dependent not only on load but also on the duration of the exercise, which can determine different levels of stress when assessing these variables ${ }^{8}$.

The associations found between CP and VT1 and VT2 are in agreement with data for UL found by Moritani et al. ${ }^{30}$. Among well-trained young students, Dekerle et al. ${ }^{8}$ found that CP was greater than VT1 and similar to VT2, with non-significant associations between CP and VT1 ( $\mathrm{r}=-0.08)$ and LV2 $(\mathrm{r}=0.07)$. In contrast to these results, Dekerle et al. ${ }^{8}$ demonstrated that the intensity at CP was similar to the VT1 intensity, while Nakamura et al. ${ }^{14}$ found that $\mathrm{CP}$ was significantly greater than VT1 ( $r$ between 0.86 and 0.93) and smaller than VT2 ( $\mathrm{r}$ between 0.79 and 0.85 ). These conflicts relating to the physiological domain of $\mathrm{CP}$ can be extended to comparisons with the intensity of maximum lactate steady state (MLSS) . $^{8}$ Although a high level of association was found between these variables ( $\mathrm{r}=0.95$ ), it has been demonstrated that $\mathrm{CP}$ is greater in intensity or that no significant differences occur between these variables ${ }^{31}$. Moreover, it was not possible to find a steady state of blood lactate concentration [la] in rectangular loadings at $\mathrm{CP}$, despite the similarity with the intensity of MLSS at $\mathrm{VO}_{2}^{6,32}$ and perceived exertion ${ }^{14}$.

Factors related to costs and the small numbers of laboratories that perform ergospirometry tests using UL ergometers hinder and sometimes even prevent physical therapists from prescribing appropriate exercises during cardiopulmonary rehabilitation programs. Methodologically, CP determination and its use as an estimate of the MLSS is advantageous for physical therapists who prescribe UL exercises during cardiopulmonary rehabilitation programs. It is easy and feasible to apply CP determinations, and to produce valid information for monitoring aerobic endurance ability and the individual 
response to training, while avoiding, for instance, problems of estimation based strictly on blood lactate values ${ }^{33}$. However, it should be noted that the results from the present study did not make it possible to establish whether CP corresponds to a greater metabolic need associated with steady lactate. Even though it was verified that $\mathrm{VO}_{2}$ stabilized under constant loading at $\mathrm{CP}$, no direct measurements of lactate were made, either at this or at other, lower or higher loads. Nonetheless, the mean time duration at $\mathrm{CP}$ was $42.9 \pm 12.9 \mathrm{~min}$ (minimum of 20 $\mathrm{min})$. None of the subjects maintained the load of $5 \%$ above $\mathrm{CP}$ for more than 20 minutes (13.7 $\pm 1.4 \mathrm{~min})$, which favors the use of CP as an approximation for the intensity of the MLSS in UL exercises. Regardless of the way in which CP is expressed, it appears to belong to a transition zone between intense and very intense domains.

Regarding the CP load, the value found for the pulmonary exchange rate was $0.98 \pm 0.02$, which corresponded to an intensity predominantly from the use of energy from carbohydrate metabolism ${ }^{34}$. Over a period of time sustaining this load, this energy path is progressively depleted, and its depletion may be the main cause of fatigue. From the time taken to reach exhaustion and the features of the UL exercises practiced at intensities higher than $\mathrm{CP}$, the main reason for terminating the exercises was correlated with increases in metabolic acidosis.

Future investigations with larger samples and involving the W-t relationship for UL exercises should be performed using different protocols, cycling paces and interruption criteria. They should also include the use of analogue scales of perceived effort and located electromyography ${ }^{10,11,24,35}$, particularly emphasizing additional studies on the relationship between the maximum lactate steady accumulation rate and $\mathrm{CP}$.

The power applied and the respective duration of a tolerance relationship for high-intensity dynamic UL exercises were characterized by a rectangular hyperbolic function. The $y$ asymptote of this relationship (CP) represented a load similar to VT2, which was likely to be sustained for a prolonged period of time and with $t$ similar to the one commonly found in LL. CP was significantly associated with indicators of aerobic metabolism, such as $\mathrm{VO}_{2}$ peak, VT1 and VT2.

\section{References:::}

1. Bosquet L, Léger L, Legros P. Methods to determine aerobic endurance. Sports Med. 2002;32(11):675-700.

2. Monod H, Scherrer J. The work capacity of a synergic muscle group. Ergonomics. 1965;8:329-38.

3. Hill DW. The critical power concept : a review. Sports Med. 1993;16(4):237-54.

4. Neder JA, Jones PW, Nery LE, Whipp BJ. The effect of age on the power/duration relationship and the intensity-domain limits in sedentary men. Eur J Appl Physiol. 2000;82(4):326-32.

5. Willians CA, Dekerle J, McGawley K, Berthoin S, Carter H. Critical power in adolescent boys and girls - an exploratory study. Appl Physiol Nutr Metab. 2008;33(6):1105-11.

6. Hill DW, Smith JC. Determination of Critical Power by Pulmonary Gas Exchange. Can J Appl Physiol. 1999;24(1):74-86.

7. Whipp BJ, Ozyener F. The kinetics of exertional oxygen uptake: assumption and inferences. Med Sport. 1998:51:139-49

8. Dekerle J, Baron B, Dupont L, Vanvelcenaher J, Pelayo P. Maximal lactate steady state, respiratory compensation threshold and critical power. Eur J Appl Physiol. 2003;89(3-4):281-8.

9. Neder JA, Jones PW, Nery LE, Whipp BJ. Determinants of the exercise endurance capacity in patients with COPD: the power-duration relationship. Am J Respir Crit Care Med. 2000;162(2Pt 1):497-504.

10. Vanhatalo A, Doust JH, Burnley M. Determination of critical power using a 3-min all-out cycling test. Med Sci Sports Exerc. 2007;39(3):548-55.

11. Capodaglio P, Bazzini G. Predicting endurance limits in arm cranking exercise with a subjectively based method. Ergonomics. 1996;39(7):924-32.

12. Calis JFF, Denadai BS. Influência das cargas selecionadas na determinação da potência crítica determinada no ergômetro de braço em dois modelos lineares. Rev Bras Med Esporte. 2000;6:1-4

13. Taylor SA, Batterham AM. The reproducibility of estimates of critical power and anaerobic work capacity in upper body exercise. Eur J Appl Physiol. 2002;87(1):43-9.

14. NakamuraFY, Borges TO, Brunetto AF, Franchini E. Correlação entre os parâmetros do modelo de potência crítica no cicloergômetro de membros superiores e no caiaque. Rev Bras Ciên Mov. 2005;13(2):41-8.

15. Celli BR. The clinical use of upper extremity exercise. Clin Chest Med. 1994;15(2):339-49.
16. Kang J, Chaloupka EC, Mastrangelo MA, Angelucci J. Physiological responses to upper body exercise on an arm and a modified leg ergometer. Med Sci Sports Exerc. 1999;31(10):1453-9.

17. Koppo K, Bouckaert J, Jones AM. Oxygen uptake kinetics during high-intensity arm and leg exercise. Respir Physiol Neurobiol. 2002;133(3):241-50.

18. Calbet JAL, Holmberg H-C, Rosdahl H, van Hall G, Jensen-Urstad M, Saltin B. Why do arms extract less oxygen than legs during exercise? Am J Physiol Regul Comp Physiol 2005;289:1448-58

19. Neder JA, Nery LE. Fisiologia Clínica do Exercício. Teoria e Prática. São Paulo: Artes Médicas; 2003.

20. Baecke JA, Burema J, Frijters E. A short questionnaire for the measurement of habitual physica activity in epidemiological studies. Am J Clin Nutr. 1982;36(5):936-42.

21. Wasserman K, Hansen JE, Sue DY, Whipp BJ, Casaburri R. Principles of exercise testing and interpretation. $2^{\mathrm{a}}$ ed. Philadelphia: Lea \& Febiger; 1987.

22. McArdle WD, Katch FI, Katch VL. Fisiologia do Exercício - energia, nutrição e performance humana. Rio de Janeiro: Guanabara Koogan; 1998.

23. Ward SA, Blesovsky L, Russak S, Ashijan A, Whipp BJ. Chemoreflex modulation of ventilatory dynamics during exercises in humans. J Appl Physiol. 1987;63(5):2001-7.

24. Hill DW, Ferguson CS. A physiological description of critical velocity. Eur J Appl Physiol Occup Physiol. 1999;79(3):290-3

25. Franklin BA. Exercise testing training and arm ergometry. Sports Med. 1985;2(2):100-19.

26. Bull AJ, Housh TJ, Johnson GO, Perry SR. Effect of mathematical modeling on the estimation of critical power. Med Sci Sports Exerc. 2000;32(2):526-30.

27. Ăstrand PO, Rodahl K, Dahl HA, Stromme SB. Textbook of work physiology. $4^{\mathrm{a}}$ ed. Champaign: Human Kinetics; 2003.

28. Wakayoshi K, Ikuta K, Yoshida T, Udo M, Moritani T, Mutoh Y, et al. Determination and validity of critical velocity as an index of swimming performance in the competitive swimmer. Eur J App Physiol Occup Physiol. 1992;64(2):153-7

29. Fawkner SG, Armstrong N. Assessment of critical power with children. Pediatr Exerc Sci. 2002:14:259-68

30. Moritani T, Nagata A, deVries HA, Muro M. Critical power as a measure of physical work capacity and anaerobic threshold. Ergonomics. 1981;24(5):339-50. 
31. Smith CG, Jones AM. The relationship between critical velocity, maximal lactate steady-state velocity and lactate turnpoint velocity in runners. Eur J Appl Physiol. 2001;85(1-2):19-26.

32. Barker T, Poole DC, Noble ML, Barston TJ. Human critical power-oxygen uptake relationship at different pedalling frequencies. Exp Physiol. 2006;91(3):621-32

33. Cligeleffer A, McNaughton LR, Davoren B. The use of critical power as a determinant for stablishing the onset of blood lactate accumulation. Eur J Appl Physiol Occup Physiol. 1994;68(2):182-7.
34. Billat VL, Sirvent P, Py G, Koraltzen J-P, Mercier J. The concept of maximal lactate steady state. A bridge between biochemistry, physiology and sport science. Sports Med. 2003;33(6):407-26.

35. Morton RH. Critical power test for ramp exercise. Eur J Appl Physiol Occup Physiol. 1994;69(5):435-8 